\title{
UMA PEDAGOGIA DO DIÁlOGO E DO CORAÇÃO: Grégoire Girard e Paulo Freire - Dois intelectuais católicos a dois continentes e dois séculos de distância
}

\author{
Peri Mesquida \\ Mauricio Eduardo Bernz \\ Abdeljalil Akkari ${ }^{(*)}$
}

\section{INTRODUÇÃO}

É possível mesmo dizer que a base teórica das primeiras obras de Freire (Educação e atualidade brasileira e Educação como prática da liberdade) e o referencial dos escritos de Girard poderiam caracterizar um nexo entre os dois autores, isso porque as duas primeiras obras de Freire têm como base teórica o iluminismo (Kant e o neokantismo - Hegel, Heidegger e os fenomenólogos e, mesmo, Emmanuel Mounier) e a fé cristã, por meio dos movimentos sociais católicos brasileiros e latino-americanos; um nexo, portanto, entre a razão e a fé. O iluminismo (Kant), as Luzes, e a fé católica, podem também ser encontrados como referencial teórico nas obras do capuchinho de Fribourg.

Ernest Naville (1950) observa que o pensamento de Kant chamava a atenção de Girard: "Sem desconhecer os pontos fracos da filosofia crítica, ele tinha uma justa admiração e um grande respeito pela intenção moral que se refletia na obra do pensador de Könisberg” (p. 8).

O Padre Girard nos seus Souvenirs (1948), diz que

A razão prática nos manda ter uma santa fé como prova da felicidade proporcional ao mérito... É à filosofia de Kant que eu devo a reforma completa do meu sistema moral e das minhas ideias sobre a natureza moral do homem. Eu percebi, então, a natureza do homem como sendo ao mesmo tempo cidadão de dois mundos. (p. 41).

Continuando, Girard expressa o seguinte pensamento:

Ao falar do dever, ele (Kant) nos faz ver que a razão prática nos obriga à santidade sob a promessa de uma felicidade proporcional ao mérito, pois esta santidade e este elemento proporcional não poderiam existir em a imortalidade e um Deus santo e todo poderoso. Enfim,

\footnotetext{
${ }^{(*)}$ Peri Mesquida. Professor titular do Programa de Pós-graduação em Educação, mestrado e doutorado da PUC-PR. Email: mesquida.peri@gmail.com.

Mauricio Eduardo Bernz. Mestrando do Programa de Pós-graduação em Educação da PUC-PR. E-mail: mauricio.bernz @colegiosmaristas.com.br.

Abdeljalil Akkari. Professor titular da Faculté de Psychologie et des Sciences de l'Éducation da Université de Genéve, Suisse.E-mail: djali198@gmail.com.
} 
que a razão prática nos apela ao dever de crer em ambos, mesmo que não possamos saber nada sobre isso. Esta filosofia não é imoral, ela não ateia como querem dizer, mas ela toma um caminho insólito para, pela virtude, chegar à religião. Na realidade trata-se de um lindo caminho, pois é aquele que toma a inocência oprimida que apoiando-se na consciência, chama ao testemunho e à justiça do céu. (1948, p. 40).

Portanto, a razão e a fé andam juntas para conduzir o homem a Deus, santo e todo poderoso. No seu livro Histoire de la pédagogie, Compayré (1920) reproduz uma declaração do Padre Girard: "Eu sou cristão porque sou filósofo e sou filósofo porque sou cristão" (COMPAYRÉ, 1920, p. 48). Isso coloca o Padre Girard em um "altar" pouco confortável diante da ortodoxia católica conservadora de Fribourg, pois ele pode ser visto como um intelectual católico adepto do iluminismo, inaugurando o que estamos chamando neste artigo de "catolicismo iluminista".

O pensamento filosófico, assim como o pensamento pedagógico de Immanuel Kant estão presentes na teoria educativa de Paulo Freire, sobretudo por meio das ideias de liberdade e de autonomia. Kant na Métaphysique des moeurs (1974), escreve:

O ser humano não pode agir senão sob a ideia da liberdade e, por si mesmo, ele é verdadeiramente livre. Isso quer dizer que para o homem todas as leis estão inseparavelmente ligadas à liberdade exatamente como se a vontade fosse definida como livre em si mesma. A todo ser racional que tem uma vontade é necessário que lhe atribuamos também a ideia de liberdade. (p. 244).

Na mesma obra o autor de Das ist aufklärung? ( $O$ que é esclarecimento?) afirma que "o homem enquanto ser racional pertence ao mundo inteligível e não pode conceber a causalidade de sua própria vontade senão a partir da liberdade... Assim, a vontade racional não pode ser uma vontade de si mesmo senão pela ideia de liberdade”. (KANT, 1974, p. 113). E ainda, quando na Critique de la raison pure (2001), Kant fala sobre a autonomia, aproximando este conceito daquele de liberdade, observa que "as decisões humanas se conectam a um arbitrium sensitivum, mas liberum e não brutum, pois o homem tem a faculdade de se determinar por si mesmo independente da coerção dos outros” (p. 589).

No seu Traité de pédagogie (2006), Kant afirma que é necessário

Acostumar o aluno a aceitar que sua liberdade seja submetida ao exame do outro e que, ao mesmo tempo, ele conduza sua liberdade. Sem esta condição seu pensamento suas ações não passarão de ideias e atos mecânicos; e assim o homem quando conclui sua educação formal, não sabe como usar a liberdade (KANT, 2006, p. 33) (KANT, 1886, p. 28).

Para Freire, "o homem é o único ser que tem capacidade de aprender; o homem é programado para aprender e assim pode inventar e reinventar sua existência” (FREIRE, 1997, p. 
126). Da mesma maneira Kant escreve no Traité de pédagogie que "o homem é a única criatura que tem necessidade de ser educada... o homem não pode se tornar verdadeiramente homem senão pela educação" (KANT, 2006, p. 14) (KANT, 1886, p. 10).

Freire via a educação como prática da liberdade, mas para ele, assim como para Kant a liberdade é limitada pela autoridade e a autoridade é limitada pela liberdade. É justamente esta relação dialética entre liberdade, vontade e autoridade que faz surgir a autonomia, isto é, a capacidade do aluno de seguir seu próprio caminho" (FREIRE; SHOR, 1996, p. 127).

Ainda: Freire, seguindo Kant, diz que "corremos o risco, quando recusamos à liberdade o direito de se afirmar, de exacerbar a autoridade ou, atrofiando esta, hipertrofiar aquela" (FREIRE, 1994, p. 23).

Freire afirma que "não é possível pensar os seres humanos fora da moral e da ética. E não é somente a razão que nos conduz a esta conclusão, mas também a fé” (1995, p. 33). Da mesma forma, Freire, quando estava exilado no Chile, portanto, quando começou a estudar em profundidade Marx e Engels, une a razão filosófica e política de Karl Marx à filosofia tomista/aristotélica de Jacques Maritain, de acordo com o testemunho de Oliveira (2005): “Onde Karl Marx cessa, Jacques Maritain toma o lugar... e afirma que somente o amor é capaz de levar o homem a alcançar a finalidade da sua existência" (OLIVEIRA et Alii, 2005, p. 269). E, dando a palavra a Freire: "Estou com Marx na mundanidade a procura de Cristo na transcendentalidade" (1997, Entrevista a Luciana Burlamaque).

Cremos que após este preâmbulo, é possível desenhar um paralelo, na forma de diálogo, entre Girard e Freire, pois as ideias que referenciaram a ação pedagógica de Freire na segunda metade do século XX se assemelham, de certa maneira, aquelas que alimentavam o pensamento e as ações pedagógicas de Girard no início do século XIX, em Fribourg, no coração da Europa revolucionária!

\section{UMA PEQUENA HISTÓRIA DE VIDA DE DOIS GRANDES EDUCADORES DISTANTES NO TEMPO, MAS PRÓXIMOS NO PENSAMENTO PEDAGÓGICO.}

Père Girard, aliás, Jean-Baptiste-Melchior-Gaspard-Balthazar Girard, nasceu no dia 17 de dezembro de 1765, em Fribourg, Suíça, em uma família de classe média superior; e morreu em 06 de março de 1850, na mesma cidade. Quinto filho de uma primogenitura de quinze crianças. Grégoire Girard, jovem (16 anos), vê o que se passa em Fribourg por ocasião da Revolução Chenaux (1781) e da agitação social, política e econômica que a Revolução estava provocando. Foi a mãe que deu a Girard as primeiras aulas, ensinando-o a ler, escrever e contar. Tão logo aprendia 
as primeiras lições, Grégoire as repassava aos irmãos mais novos. Girard estudou no Colégio dos Jesuítas, em Fribourg. No entanto, tomou a decisão de seguir a carreira sacerdotal na ordem dos franciscanos. Seus estudos de teologia, filosofia e direito eclesiástico, Grégoire realizou em Würzburg, Alemanha.

Paulo Reglus Neves Freire nasceu em 19 de setembro de 1921, em Recife, Estado de Pernambuco, Brasil, filho de uma família de classe média. Faleceu em 02 de maio de 1997, em São Paulo. Terceiro filho de uma prole de quatro filhos e filhas, Paulo Freire, menino ( 8 anos), sentiu no próprio corpo o que é ter fome por ocasião da chamada Revolução Vargas (1930) que anunciava o fim da supremacia política da oligarquia agrária e o início da presença política e econômica no cenário brasileiro de outra oligarquia, esta, urbana e industrial. Freire recebeu da mãe as primeiras lições à "sombra de uma mangueira". Mas, sua escolarização inicial se deu em uma escola primária pública, e o secundário, em uma instituição privada, com uma bolsa de estudos. Na Universidade Federal de Pernambuco fez o curso de direito.

Dessa maneira, católico, Girard segue o caminho de uma ordem religiosa, Freire, católico, o caminho das ciências jurídicas. Capuchinho, conhecedor da teologia, da filosofia e do direito, Girard se torna educador, colocando-se ao lado dos pobres, sem jamais deixar a Ordem religiosa dos franciscanos; advogado, Freire será pedagogo, defendendo a causa dos excluídos da sociedade estabelecida, abandonando a Ordem dos advogados.

\section{UMA PEDAGOGIA DO CORAÇÃO: OPÇÃO EM FAVOR DOS DESFAVORECIDOS}

As obras do Padre Girard mostram que ele sustenta uma pedagogia que parte do coração do educador e se dirige ao coração das crianças; o coração visto como a sede dos sentimentos, mas também da razão e da fé: "Nós nos dirigimos ao coração dos educandos, a sua consciência e ao seu entendimento (raciocínio)" (1846, p. 109). Portanto, ele coloca a instrução ao serviço da educação do coração, pois "a regra está posta: formar o espírito e o coração dos educandos" (idem, p. VIII). Para ele, "a cultura intelectual deve ser posta ao serviço da educação do coração" (ibidem, p. 25). O Padre Girard apela para que nas escolas que ele dirige e nas escolas públicas do Cantão de Fribourg, "todos os elementos constitutivos da instrução sejam colocados ao serviço da cultura, e esta ao serviço da educação do coração" (ibidem, p. 24). É importante salientar que da mesma maneira que para Pestalozzi, contemporâneo e conterrâneo de Girard, o coração está no centro da sua trilogia: cabeça, coração e mão, ele também é o elemento central da pedagogia girardina, pois o coração é o órgão de onde partem os sentimentos e as ações de caridade, do amor, pois a obra do Padre Girard é 
uma obra franciscana de amor em favor dos pobres: uma obra de caridade (corde - latim - kardia grego - charité - francês - caridade - português) como obra em favor dos desfavorecidos, dos pobres. Com a palavra Grégoire Girard: "Vos dar conhecimento e talentos não é tudo, é importante sobretudo formar o vosso coração no amor e fazer que vossos filhos sejam sábios, honestos e bons...é a teologia do coração que nós pensamos ensinar ás crianças” (GIRARD, 1806, p. 13 e 104).

Assim, Girard se torna defensor da escola pública para todos, dos orfanatos à escola primária: uma opção em favor dos desfavorecidos.

A tradução inglesa do livro de Paulo Freire À sombra desta mangueira (1995), traz o título de Pedagogy of the heart (1998), isto é Pedagogia do coração. Isso porque Freire defende a ideia que a pedagogia do coração é aquela que está "encharcada" de amor. Daí que uma pedagogia do coração é uma pedagogia do amor, da caridade em favor dos pobres, dos oprimidos, dos excluídos. Em uma entrevista para o jornal Pasquim, em 1978 (p.11), Freire declara: "Para mim o amor é indispensável, pois ele é uma dimensão do ser vivo... a revolução em favor dos excluídos é uma ação de amor". Na mesma entrevista Freire observa que:

Quando nós nos propomos a praticar o amor como caridade em favor dos pobres as pessoas podem dizer que se trata de loucura. O apóstolo Paulo escreveu que o Evangelho é loucura para os descrentes. Mas Blaise Pacal afirmava que o coração tem razões que a própria razão desconhece (p. 12).

Assim, as "razões" do coração de Freire estavam condicionadas pela ação pedagógica amorosa, caritativa, em favor dos pobres, dos oprimidos. Por isso, Freire pode ser visto como um profeta da educação popular - uma opção pelos pobres, os excluídos -, denunciando a opressão e anunciando sua libertação pela educação e a instrução.

\section{A MÃE, MESTRA E MODELO: UMA TEOLOGIA PEDAGÓGICA E UMA PEDAGOGIA TELEOLÓGICA}

Grégoire Girard conta a história da "mulher de Morat” (cidade suíça do Cantão de Fribourg), uma senhora que levava para as crianças, entre elas Jean-Baptiste, um "presente na sua cesta de legumes". Mas esta senhora era protestante e o preceptor de Jean-Baptiste perguntado pelo menino sobre a salvação desta mulher respondeu que ela não pertencia à igreja católica, portanto estava condenada ao fogo do inferno. Jean-Baptiste perguntou a sua mãe se o preceptor estava certo, ao que ela respondeu: "o preceptor é um burro: o bom Deus não condena as pessoas boas. Eis a verdade". Esta posição da mãe de Girard viria a ser no futuro o que ele passou a chamar de “teologia da minha mãe" (GIRARD, 1948, p. 10-11). Na realidade, uma teologia que tomará a 
forma de uma teologia pedagógica para o Padre Girard, uma pedagogia de abertura "ecumênica" e de amor pelos desfavorecidos. O Padre Girard conta que sua mãe praticava, em casa, quando JeanBaptiste era criança, o que mais tarde seria conhecido como "método de ensino mútuo", pois ela pedia a Jean-Baptiste que ensinasse aos irmãos mais novos o que ele havia aprendido dela e do preceptor. Trata-se, portanto, de uma teologia pedagógica que guiará o Padre Girard durante a vida. Mas, seria também, uma pedagogia teológica, pois, ela orientou a ação pedagógica de Girard pelo caminho da razão e da fé em direção à Verdade. Nos seus Souvenirs (1948), o Padre Girard revela quem era sua mãe: "Minha mãe, mulher espiritual, viva, carinhosa, forte... cujos olhos, os ouvidos e o coração estavam em todos os lugares com seus filhos...eu cresci sob o teto paternal com um orgulho masculino... mas a mãe é, na família, a primeira mestra da língua e do sentimento" (GIRARD, 1948, p. 10-11; 1846, p. 1).

Para Freire, sua mãe foi mestra e modelo de amor e caridade que deveria ser seguido, pois foi ela quem o ensinou a ler e a escrever de uma maneira que ele jamais esqueceria: "Meu pai, militar, não era autoritário, mas sua presença estava em todo o lugar na casa; no entanto, era minha mãe quem conduzia a casa. Ela me ensinou a escrever as primeiras palavras" (FREIRE, 2003, p. 38). Na realidade ela ensinou Freire a ler escrevendo e a escrever lendo, metodologia que ele irá reproduzir no seu método de alfabetização de adultos, eliminando o dualismo de ler e, depois, escrever...se possível. Isso à sombra de uma mangueira. Perguntava Freire: "É preciso um espaço apropriado para o ensino e a aprendizagem?” (2003, p. 122). Ele percebeu que podemos ensinar e aprender em todo o lugar sem que haja necessidade de um espaço apropriado. Daí, os círculos de cultura nos quais os educandos aprendem por meio do diálogo entre eles e o educador. Freire aprendeu com sua mãe a ter compaixão pelos oprimidos, os pobres, os que têm fome, isso porque depois da morte do pai era a mãe quem providenciava o sustento da casa e a alimentação da família. (1995, p. 38).

\section{Uma pedagogia antropológica ou uma antropologia pedagógica?}

A atividade pedagógica do Padre Girard está centrada no homem (genérico). O homem é o ponto de partida e o ponto de chegada da reflexão e da ação pedagógica girardinas. Para Girard: "tudo na terra deve estar ordenado na direção do homem como sendo o seu centro e o que tem de mais elevado" (GIRARD, 1816, p. 720). A centralidade do ensino no homem concreto, geograficamente localizado e historicamente situado, é essencial nas escolas dirigidas pelo Padre Girard: "Em nossas três escolas é sempre o homem que nós teremos e é, portanto, ele que devemos cultivar" (1816, p. 721). Outra observação de Girard no seu Curso de Língua, acentua esta visão antropológica: “O curso de língua nos levará aos seguintes objetivos: o homem como espírito 
nobre...o Salvador dos homens, a moral, a infância, como ponto de chegada" (GIRARD, 1846, p. 110). Podemos, a partir dessas citações, chegar à constatação que a visão Girard da ação pedagógica, sua natureza e sua finalidade, está circunscrita em um neo-humanismo cristão cuja origem seria o pensamento iluminista do século XVIII, em particular o iluminismo kantiano.

Paulo Freire defende a tese de que o homem historicamente situado, deve ser o ponto de partida de toda a ação pedagógica: "o homem e suas relações com o mundo e com os outros homens é o ponto de partida e o ponto de chegada de nossa prática pedagógica...Trata-se de uma luta em favor da humanização do homem oprimido" (FREIRE, 2012, p. 67 e 30). Portanto, para Freire, não há prática pedagógica libertadora senão por meio de uma ação educativa centrada no homem; é a humanização.

Quando afirmamos que Freire, à semelhança de Girard, situa o homem geográfica e historicamente, vendo-o como ser de relação, com o mundo e com os outros homens, indica que a ação pedagógica humanista parte de uma reflexão sobre a natureza e a realidade do homem para se expressar em uma prática educativa centrada no homem:

A partir das relações do homem com a realidade, resultantes de estar nela, pelos atos e criação, recriação e decisão, vai ele dinamizando o seu mundo. Vai dominando a realidade. Vai humanizando-o. Vai acrescendo a ela algo de ele mesmo é fazedor. Vai temporizando os espaços geográficos. Fez cultura. E é ainda o jogo destas relações do homem com o mundo e do homem com os homens, desafiado e respondendo ao desafio, alterando, criando, que não permite imobilidade, a não ser em termos de relativa preponderância, nem das sociedades nem das culturas. E, na medida em que cria, recria e decide, vão se confirmando as épocas históricas. É também criando, recriando e decidindo que o homem deve participar destas épocas. E, o ato pedagógico deve, assim, ter o homem como referência (FREIRE, 2001, p. 51)

Podemos concluir que Freire desenvolve uma verdadeira pedagogia antropológica. Ou uma antropologia pedagógica?

\section{GRÉGOIRE GIRARD E PAULO FREIRE: A PRÁTICA EDUCATIVA, A DIDÁTICA, O MÉTODO.}

Inicialmente é fundamental mostrar a importância que Girard e Freire atribuem à educação na formação do homem, na sua humanização. Girard escreve que "nós não temos a ridícula pretensão de acreditar que nossa instrução transforma, como que por encanto, crianças em homens maduros, mas ela terá feito bastante se por meio do ensino, os jovens se tornarem menos infantis (sem fala)" (GIRARD, 1846, p. 109). Em outra obra, Girard (1816) apresenta um conceito do que, para ele, seria a educação: "a educação é uma preparação para a vida a fim de que o homem possa 
realizar aqui as tarefas temporais, mas que possa construir ao mesmo tempo seu destino eterno" (p. 120).

Freire, na Pedagogia do oprimido (2012), constata que "se a educação não é o motor das transformações sociais, estas não se produzem sem a ajuda da educação".

\section{Grégoire e Freire: A ação educativa (1): o universo cultural dos estudantes fornece as palavras geradoras.}

Padre Girard: A Gramática da Campanha (Grammaire des campagnes, à l'usage des écoles rurales du Canton du Fribourg) (1821) mostra que para alfabetizar as crianças é conveniente fazêlo "com palavras e coisas do meio rural", isto é, o ensino da leitura e da escrita é um processo que começa onde as crianças se encontram com palavras que fazem parte de seu contexto cultural. Por isso, Girard esclarece: "Nós pedimos, em nome da didática, que os estudantes sejam chamados a fornecer sua contribuição para a escolha do vocabulário" (GIRARD, 1846, p. 57). Trata-se de uma ação cultural em favor do aprendizado dos estudantes. Mas, Père Girard defende também que as palavras levadas pelos estudantes sejam objeto de problematização pelo diálogo e pela ação "reflexiva": "Na vida o estudante não terá a regra diante dele, mas o problema. Faz-se portanto necessário colocar a escola na mesma posição e lhe dar os meios de resolver...as questões que se apresentarão" (GIRARD, 1846, p. 58). Assim, é importante começar pela prática na direção da teoria, do conhecido ao desconhecido do simples ao complexo: "Todo mundo sabe que partindo do conhecido para o desconhecido, do sensível para o abstrato, a boa educação parte do pai visível da criança ao Pai invisível”, pois "o espirito humano tende naturalmente a se desenvolver cada vez mais, do simples para o complexo e do pequeno para o grande" (GIRARD, 1846, p. 55-56). Girard, o católico ilustrado, adota, portanto, a intuição/indução como método teórico-prático: “Desde tempos muito foi escrito sobre o conhecimento intuitivo por onde a instrução da criança deve começar... este conhecimento mostra os objetos sensíveis, ajuntando o signo à coisa escrita" (GIRARD, 1846, p. 48). Trata-se, pois, não somente de um ensino progressivo, por gradação, mas também de uma antecipação da escola ativa de Claparède e da Escola Nova que dão ênfase ao método intuitivo/indutivo.

Paulo Freire, da mesma forma que Girard, defende uma ação educativa que parte do universo cultural dos iletrados e dos problemas reais da vida: "É necessário fazer com que as palavras, as frases, se originem do contexto vivido do analfabeto" (FREIRE, 1981, p. 17-19). Em Educação como prática da liberdade (1999), Freire escreve: "Defendo uma educação que se origina dos problemas concretos da vida, pois ela é revolucionária e assim grávida da esperança” (1999). Assim, Freire, católico ilustrado do século XX (Mounier, Marcel, Maritain), nesta obra, 
adota a indução como método teórico: “A educação no processo de alfabetização parte sempre do concreto, do vivido e, pois, da realidade. É importante que as palavras tenham tudo a ver com a vida do educando" (idem, 1999).

\section{Girard e Greire: A ação educativa (2): os círculos de cultura, o ensino mútuo, a cabeça como vaso.}

Grégoire Girard torna-se "arquiteto" para adaptar a escola dos franciscanos em Fribourg à prática pedagógica que ele queria desenvolver, seja fazendo uso do "método" de ensino mútuo de Bell e Lancaster, colocando os estudantes em torno de mesas ou, então, de pé, em círculos, seja para praticar a pedagogia progressiva em salas adaptadas a esta finalidade: "É assim nosso curso de língua materna... ele objetiva desenvolver a cultura do espírito e do coração...a serviço da cultura e do coração... os estudantes estudam ativamente, uns em círculos, outros pela escrita, ao redor de mesas" (1846, p. 105, 154, 155). Então, as crianças compondo círculos, dialogavam umas com as outras e com o monitor, a serviço da cultura... e da cultura do coração. Seriam os círculos de Girard círculos de cultura, como dois séculos mais tarde, propôs Paulo Freire? Se a resposta for afirmativa, podemos dizer que os círculos pedagógicos de Girard tinham necessidade de um espaço que lhes fosse apropriado enquanto os círculos de cultura de Freire não exigiam qualquer tipo de espaço especial, pois os(as) educandos(as) se reuniam mesmo que fosse "à sombra de uma mangueira". Em todo o caso, os círculos educativos de Girard reunião um grupo de crianças "animadas" por um monitor segundo o método de ensino mútuo. Os círculos de cultura de Freire eram "animados" por um “animador cultural”, não raro um(a) educando(a) mais adiantado(a). A prática pedagógica nos círculos de cultura se desenvolve pelo diálogo entre os(as) educandos(as) e entre os(as) educandos(as) e o animador cultural, o "monitor". Partindo das palavras e sua verbalização, a leitura e a escrita (ler escrevendo e escrever lendo), a didática do Padre Girard queria formar a consciência das crianças, pois para ele "é fundamental...ensinar a julgar e a pensar com justeza" (GIRARD, 1846, p. 35), seguindo, dessa maneira, o que a mãe faz quando pratica sua função de mestra, pois “ela (mãe) quer despertar a consciência das crianças” (p. 14). Da mesma forma Freire quer formar a consciência dos "iletrados". Ele chegou mesmo a forjar com um sociólogo brasileiro (Álvaro Vieira Pinto), um neologismo para traduzir a ação pedagógica de formar a consciência: “conscientização" (FREIRE, 1979, 16), isto é, como diria Girard, a formação de uma consciência da justiça, da honestidade, do justo, capaz de levar o (a) educando (a) a se tornar autônomo (a), a pensar por si mesmo (a), pois

Dessa forma eles(as) construirão o hábito de refletir sobre suas próprias ideias e sobre aquelas que lhes vêm de fora. Assim, aprenderão desde cedo a se separar de pessoas que não pensam, que não sabem senão repetir o verdadeiro e o falso que soam nos seus ouvidos sem serem 
capazes de fazer a distinção de uns e outros. Como não pensam senão pelos outros, não passam de servis imitadores do que vêm os outros fazerem. Assim, o homem não estão lá, ele não é mais que um macaco (GIRARD, 1846, p. 128-129).

Mais ainda: o mestre deveria sempre ir à frente para mostrar o caminho aos estudantes, mas rapidamente os(as) alunos(as) deveriam seguir sua própria inteligência e eles (elas) mesmos(as) fazerem sua gramática e sua lógica (GIRARD, 1846, p. 27-28) (Seria a zona de desenvolvimento potencial (ZDP), de Vygotsky, "avant la lettre”?). Isso porque, para Girard, a cabeça dos alunos não é um vaso: "as mentes jovens não são vasos nos quais podemos depositar tudo o que queremos e que, em seguida, colocamos para fora para encontrar o que havíamos depositado" (GIRARD, 1846, p. 92). Paulo Freire também queria formar para a autonomia (Pedagogia da autonomia, 1997) de maneira que o (a) educando (a) pudesse tomar decisões por si mesmo (a): ele queria restituir o homem a si mesmo (como Rousseau, segundo Pestalozzi, Écrits sur la méthode, III, p. 179). Freire não fala de cabeça - mente - como vaso, ele a percebe, antes, como banco (mais moderno!): “O (a) educando (a) não é como um banco, portanto o ensino não é a ação de fazer depósitos na cabeça dos(as) alunos(as). O ato pedagógico não é uma educação bancária” (FREIRE, 2012, p. 33). Aliás, essa concepção podemos encontrar nas obras morais de Plutarco (45-120) e também em Pestalozzi. Plutarco observa que

O espírito não é como uma jarra que basta encher. Semelhante às matérias combustíveis, ele precisa antes de tudo de um alimento que o aqueça, que dê estímulo as suas faculdades e o anime a caminhar na direção da pesquisa da verdade” (PLUTARCO, 1844, p. 38).

\section{CONSIDERAÇÕES FINAIS}

Finalmente, lembremos que tanto Girard quanto Freire, seguindo João Amós Comenius (Komenskí), insistiram no uso de imagens enquanto recurso didático/pedagógico. Girard justificava o uso de imagens pelo fato que "o conhecimento intuitivo, por onde a instrução da criança deve começar", pede que os professores "mostrem um após outro os objetos... e juntem o signo à coisa" (GIRARD, 1846, 52). E, comenta que a sua mãe, sua primeira mestra, dizia:

Associe o signo de chamada à coisa a fim de que ambos se unam estreitamente no espírito da criança e, na ausência do objeto concreto, a palavra possa substituí-lo. Assim, a criança pensa e fala. A palavra e o pensamento são, dessa maneira reproduzidos (GIRARD, 1846, p. 3).

Por isso, "procuramos colocar no seu espírito (da criança) imagens e pensamento verdadeiros e justos" (idem, p. 12). É importante sempre "reunir a palavra escrita à palavra vista e pronunciada: a escrita fixa o pensamento e seu signo" (idem, p. 35). 
Quando Paulo Freire iniciou sua prática de alfabetização de adultos pediu a um artista brasileiro, Francisco Brennand, que desenhasse quadros com imagens e palavras a serem utilizados na alfabetização. Dessa forma os educandos(as) veriam a palavra e sua imagem. Aprenderiam, assim, a ler escrevendo e a escrever lendo. Da mesma forma Girard escreve: "faz-se necessário que o nosso aluno aprenda a escrever lendo e a ler escrevendo" (GIRARD, 1953, p. 6). E, Freire, concluindo: "Ler para depois escrever pode levar o homem a não dominar a escrita. Nosso método ensina o iletrado a ler escrevendo e a escrever lendo" (FREIRE, 1999, p. 134). Girard e Freire: orientações que poderiam ser adotadas pelos(as) professores(as) alfabetizadores(as) nos dias de hoje. 


\section{REFERÊNCIAS}

COMPAYRÉ, G. Histoire de la pédagogie. Paris: Ed. Mellotée, 1920.

FREIRE, P. À sombra desta mangueira. São Paulo: Olho d’Água, 1995.

; SHOR, I. Medo e ousadia. Rio de Janeiro: Paz e Terra, 1996.

Pedagogia da autonomia: saberes necessários à prática educativa. Rio de Janeiro: Paz e Terra, 1997.

Uma pedagogia do amor. Entrevista. Rio de Janeiro: Pasquim, 1978.

Entrevista a Luciana Burlamaqui. São Paulo: TVPUC-SP, 17/04/1997.

Pedagogy of the heart. New York: Continuum, 1998)

Educação e atualidade brasileira. Rio de Janeiro: Paz e Terra, 2001.

Ação cultural para a liberdade e outros escritos. Rio de Janeiro: Paz e Terra, 1981.

Conscientização: teoria e prática da libertação. São Paulo: Cortez \& Moraes, 1979.

Cartas a Cristina: reflexões sobre minha vida e minha praxis. São Paulo: Ed. Unesp, 2003.

Pedagogia do oprimido. São Paulo: Paz e Terra, 2012.

Educação como prática da liberdade. Rio de Janeiro: Paz e Terra, 1999.

GIRARD, P.G. Quelques souvenirs de ma vie avec de réflexions. Fribourg: Société Fribourgeoise d'Éducation, 1948.

. De l'enseignement régulier de la langue maternelle dans les écoles e les familles. DEZOBY, E. Magdeleine \& Cie. Paris: Librairies-Éditeurs, 1846.

Discours de cloture prononcés par le R.P. Grégoire Girard, 1805-1822. Fribourg: Société Fribourgeoise d'Éducation, 1950.

. Méthodes et procédés d'éducation. Fribourg: Société Fribourgeoise d'Éducation, 1953.

Piller, 1821.

Grammaire des campagnes, à l'usage des écoles rurales du Canton du Fribourg. Paris: François-Louis

KANT, E. Fundamentos da metafísica dos costumes. São Paulo: Abril Cultural, 1974.

Sobre pedagogia. Piracicaba: Edunimep, 2006.

Traité de pédagogie. Paris: Félix Alcan Éditeur, 1886.

Critique de la raison pure. Paris: Flamarion, 2001.

NAVILLE, E. Notice bibliographique sur le Père (Grégoire) Girard de Fribourg. Genève: Joël Cherbuliez, Libraire du Éditeur, 1850

OLIVEIRA et Alii. Introdução ao pensamento filosófico. São Paulo: Loyola, 2005.

PESTALOZZI, J. H. Écrits sur la méthode, III. Le Mont sur Lausanne: Éd. Loisirs et Pédagogie, 2009.

PLUTARQUE. Oeuvres morales. Paris: Chez Lefevre, 1844. 


\section{RESUMO}

Apesar das teorias pedagógicas e do pensamento educativo de Girard e Freire estarem inscritos em contextos sociais, políticos, culturais e temporais diferentes, podemos perceber uma aproximação das ideias, das teorias e das práticas educativas, assim como da visão que esses dois intelectuais católicos e educadores sociais tinham no que diz respeito aos métodos pedagógicos e aos objetivos da educação e do ensino. Podemos mesmo dizer que há uma comunhão de ideias e de pontos de vista. Sua fé católica, apesar de ambos fundamentarem também seu pensamento filosófico e pedagógico em autores acatólicos, como Immanuel Kant (entre outros no caso de Freire), os aproximava: ambos tinham certeza de que a boa pedagogia era uma pedagogia que partia do coração do educador na direção do coração do educando. Daí que Freire defendia uma amorosidade enérgica (Mesquida, 2016) e Girard, uma pedagogia do amor centrada no coração. A ação pedagógica tanto de Freire quanto de Girard, parte da cultura, isto é, do meio em que o educando vive. Por isso, ambos acreditavam na força das palavras geradoras (de cultura) como elementos linguísticos e culturais capazes de alfabetizar as pessoas, crianças (Girard), jovens e adultos (Freire). Além disso, seus projetos pedagógicos visavam pessoas da mesma classe social: os pobres, no projeto pedagógico de Girard; os oprimidos, na pedagogia de Freire. Por isso os dois intelectuais da educação pensaram uma pedagogia visando os excluídos da sociedade organizada. Girard, procurando universalizar seu pensamento pedagógico na escola pública Suíça; Freire, desencadeando uma campanha nacional de alfabetização de adultos no Brasil (1963) e, mais tarde, também em países africanos tornados independentes, como Guiné Bissau e Cabo Verde. Portanto, se o contexto cultural, histórico e social, distanciava Girard e Freire, o pensamento educacional e sua paixão pela educação do povo os aproximam.

Palavras-chave: pedagogia do coração; diálogo; Girard/Freire.

\section{UNA PEDAGOGÍA DEL DIÁLOGO Y DEL CORAZÓN: GRÉGOIRE GIRARD Y PAULO FREIRE - DOS INTELECTUALES CATÓLICOS A DOS CONTINENTES Y DOS SIGLOS DE DISTANCIA. RESUMEN}

A pesar de las teorías pedagógicas y el pensamiento educativo de Girard y Freire están inscritos en uno contexto social, político y cultural diferente, podemos ver una aproximación de las ideas, de las teorías y de las prácticas educativas, así como la visión que estos dos intelectuales católicos y educadores tenían con respecto a los métodos de enseñanza y los objectivos de la educación y la enseñanza. Incluso podemos decir que existe una comunión de ideas y puntos de vista. Su fe católica, aunque ambos también justifiquen su pensamiento filosófico y pedagógico en autores acatólicos, como Immanuel Kant (entre otros, en el caso de Freire), los acercava uno del otro: ambos estaban seguros de que la buena pedagogía era una pedagogía que sale del corazón del educador hacia el corazón del estudiante. Por lo tanto Freire defendía una amorosidad energica (Mesquida, 2016) y Girard, una pedagogía del amor centrada en el corazón. La acción pedagógica tanto de Freire como de Girard, parte de la cultura, que es el contexto en el que vive el estudiante. Por lo que ambos creían en el poder de las palabras generadoras (de cultura) como elementos lingüísticos y culturales capaces de alfabetizar las personas: los niños (Girard), adultos y jóvenes (Freire). Por otra parte, sus proyectos educativos eran dirigidos a personas de la misma clase social: los pobres, en el proyecto educativo de Girard; los oprimidos, en la pedagogía de Freire. Así que los dos intelectuales de la educación pensaran una pedagogía dirigida a los excluidos de la sociedad organizada. Girard, buscó universalizar su pensamiento pedagógico en la escuela pública Suiza; Freire, desencadenó una campaña nacional de alfabetización de adultos en Brasil (1963) y los países africanos que venían de conquistar su independencia, como Guinea Bissau y Cabo Verde. Así que si el contexto cultural, histórico y social, los hacía distantes uno del otro, el pensamiento educativo y su pasión por la educación de las personas los hacía próximos.

Palabras-clave: Pedagogía del corazón; diálogo; Girard / Freire. 


\section{UNE PÉDAGOGIE DU DIALOGUE ET DU COEUR: GRÉGOIRE GIRARD ET PAULO FREIRE - DEUX INTELECTUELS CATHOLIQUES À DEUX CONTINENTS ET À DEUX SIĖCLES DE DISTANCE. \\ RÉSUMÉ}

Malgré le fait que les théories pédagogiques et les pensées éducatives de Girard et Freire se sont inscrites dans des contextes sociaux, politiques, culturels, géorgraphiques e temporels différents il y a quand même un rapprochement d'idées, de théories et de leur pratique éducative, ainsi que du but de l'éducation et de l'enseignement. Nous pouvons même dire qu'il y a une certaine communion d'idées, d'approches. Il y a aussi le fait que leurs projets pédagogiques visaient les personnes d'un même milieu social: les pauvres, chez Girard; les opprimés (pauvres), chez Freire. Donc les deux pédagogues ont pensé une pédagogie pour les exclus de la société organisée. Ainsi, si le contexte culturel, historique et social éloigne Girard et Freire, la pensée éducative et leur passion pour l'éducation du peuple les rapproche.

Mots-clés: Pédagogie du coeur; dialogue; Girard/Freire.

\section{A PEDAGOGY OF DIALOGUE AND HEART: GRÉGOIRE GIRARD AND PAULO FREIRE - TWO CATHOLIC INTELLECTUALS ON TWO CONTINENTS AND TWO CENTURIES AWAY. \\ ABSTRACT}

Despite the pedagogical theories and educational thought of Girard and Freire are enrolled in social, political, geographical, cultural and different contexts and times, we can see a rapprochement of the ideas, theories and educational practices, as well as the vision of these social educators in the regard to the purpose of education and teaching. We can even say that there is a communion of ideas and views. Moreover, their educational projects aimed at people of the same social class: the poor, in the educational project of Girard; the oppressed, in Freire's pedagogy, hence the fact that the two teachers thought a pedagogy aimed at those excluded from organized society. So if the cultural, historical and social distance of Girard and Freire, educational thinking and his passion for the education of the people approaching them.

Keywords: Pedagogy of the heart ; dialogue ; Girard/Freire. 